
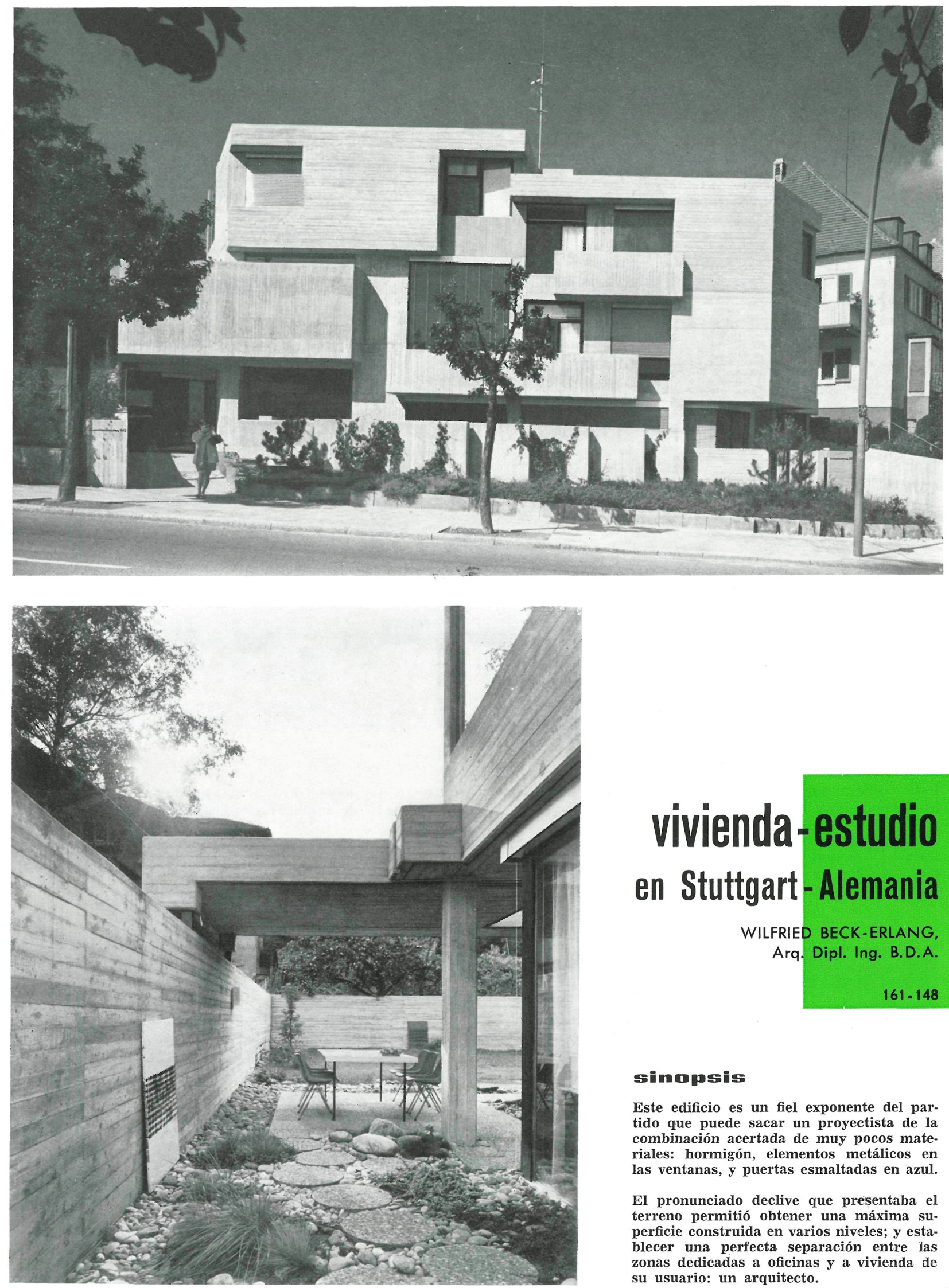

\title{
vivienda-estudio en Stuttgart-Alemania
}

WILFRIED BECK-ERLANG, Arq. Dipl. Ing. B.D.A.

161.148

\section{simopsis}

Este edificio es un fiel exponente del partido que puede sacar un proyectista de la combinación acertada de muy pocos materiales: hormigón, elementos metálicos en las ventanas, y puertas esmaltadas en azul.

El pronunciado declive que presentaba el terreno permitió obtener una máxima superficie construida en varios niveles; $y$ estaberficie construida en varios niveles; y estazonas dedicadas a oficinas y a vivienda de su usuario: un arquitecto. 


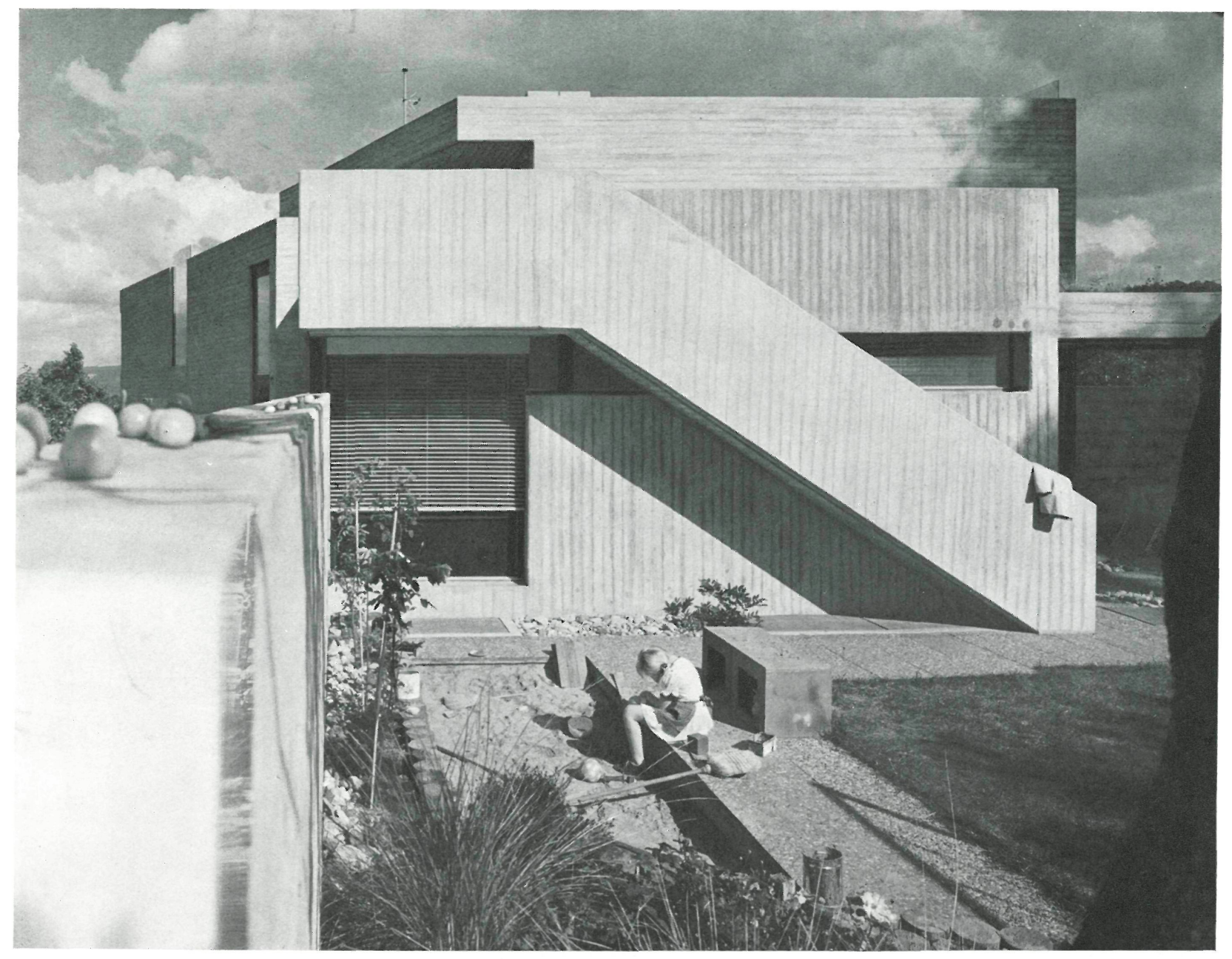

Este edificio que aloja la vivienda y las oficinas de un arquitecto ha sido construido en Marquardstr/Planckstr, Stuttgart, sobre una pequeña parcela - en esquina - situada al borde de una carretera muy transitada.

El pronunciado declive que presenta el terreno permitió establecer una perfecta separación entre las zonas dedicadas a oficinas y las destinadas a vivienda, creando varios niveles, lo cual proporciona, además, una gran movilidad plástica al edificio.
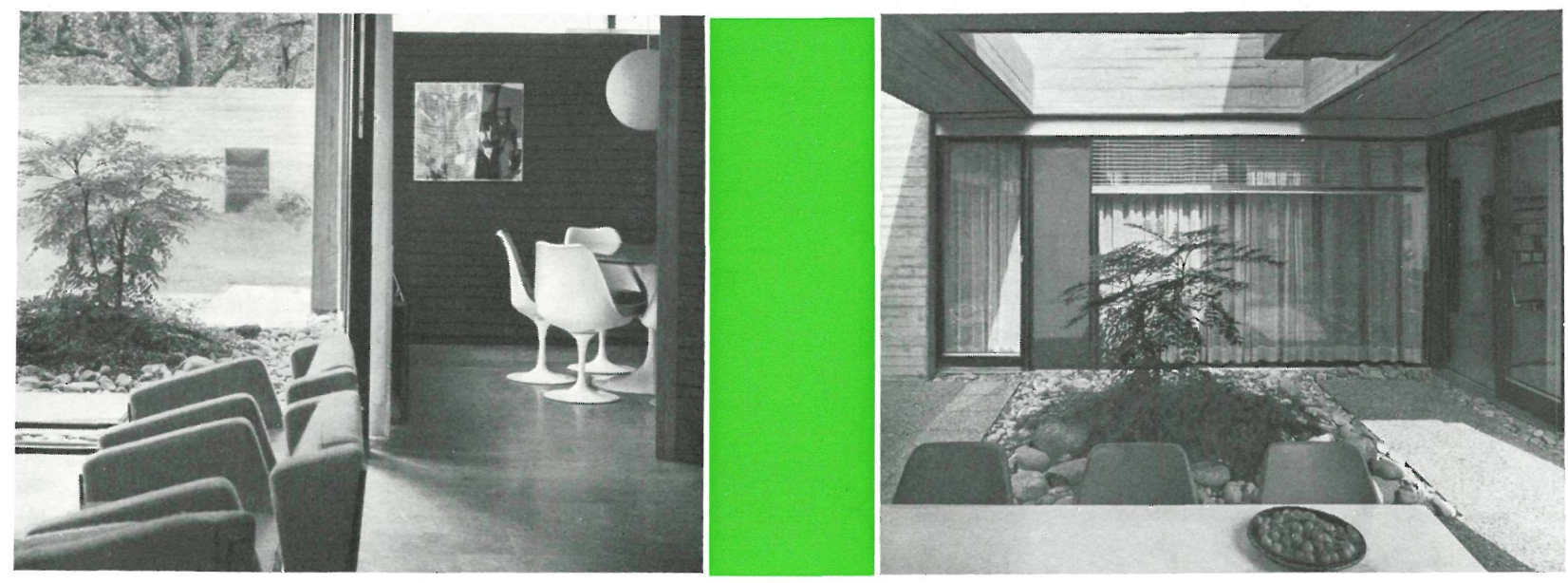


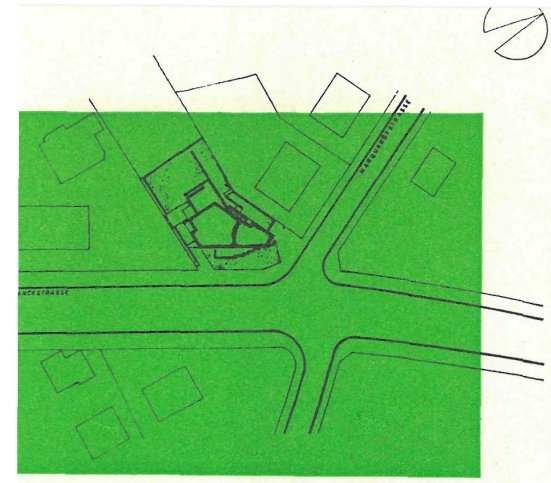

empolazcumienta

El problema de aislar el espacio interior de los ruidos procedentes del tráfico exterior ha sido tratado con especial cuidado, solucionándose de la forma más idónea ya que, por su situación junto a una vía muy frecuentada, era preciso esta especial atención.

La construcción aparece realizada según un sistema «duplex»:

- El módulo inferior alberga:

- en la planta de semisó tano: un despacho, archivo, trastero, cuarto de la calefacción, etc.;

- en la planta baja: la entrada al estudio, zonas de ingreso y de visitas, secretaría, sala de con ferencias, guardarropas, sala de dibujo superior sala de dibujo inferior despacho principal, archivo, garaje, etc.

- Y en el módulo superior: el vestíbulo de la zona de vivienda, comedor, estar sala de trabajo, habitación de huéspedes, terraza cubierta, etc.

Finalmente, en la planta superior se distribuyen: el cuarto de los niños, dormitorio de los padres, baño, cocina, etc.

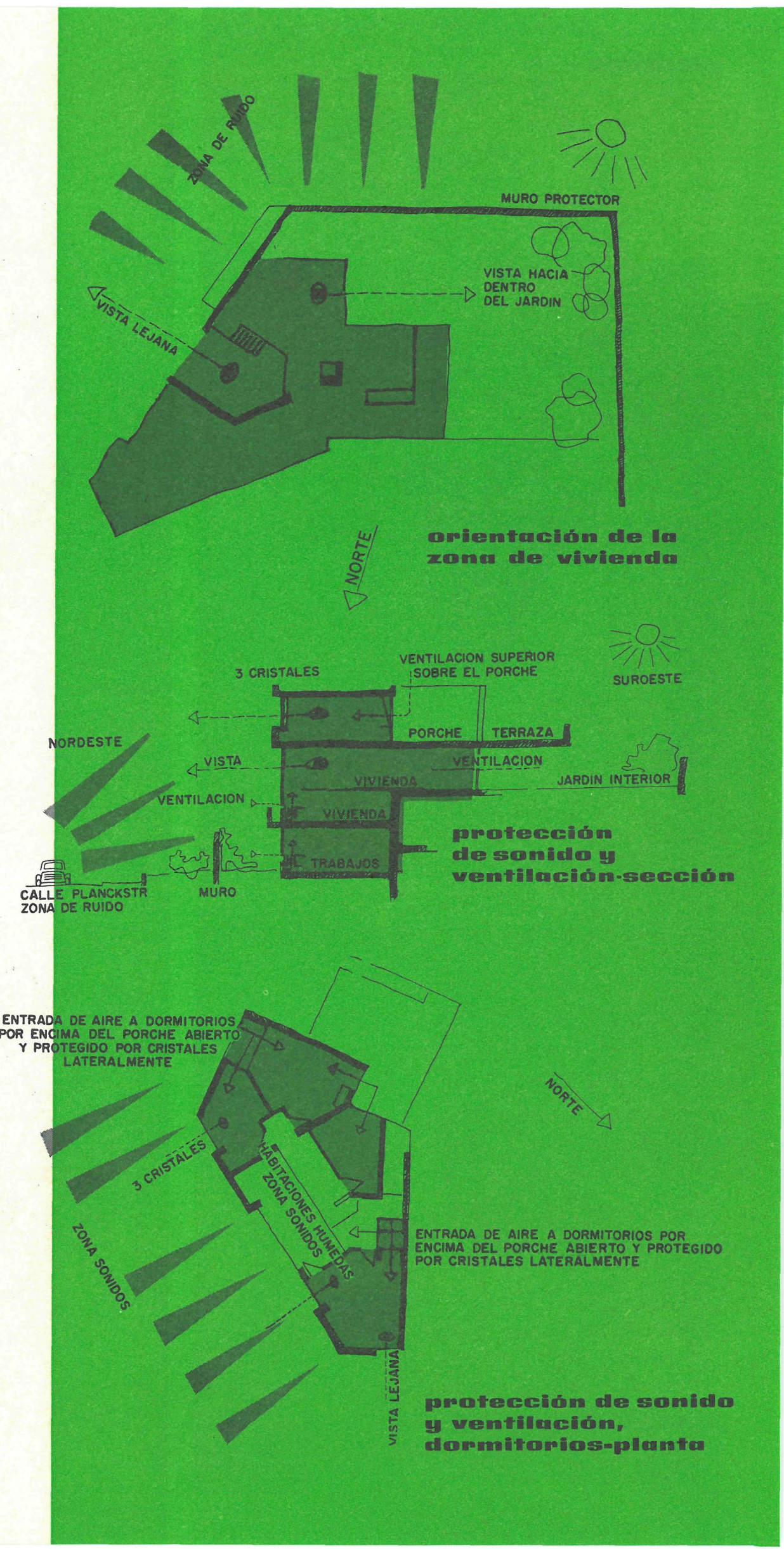




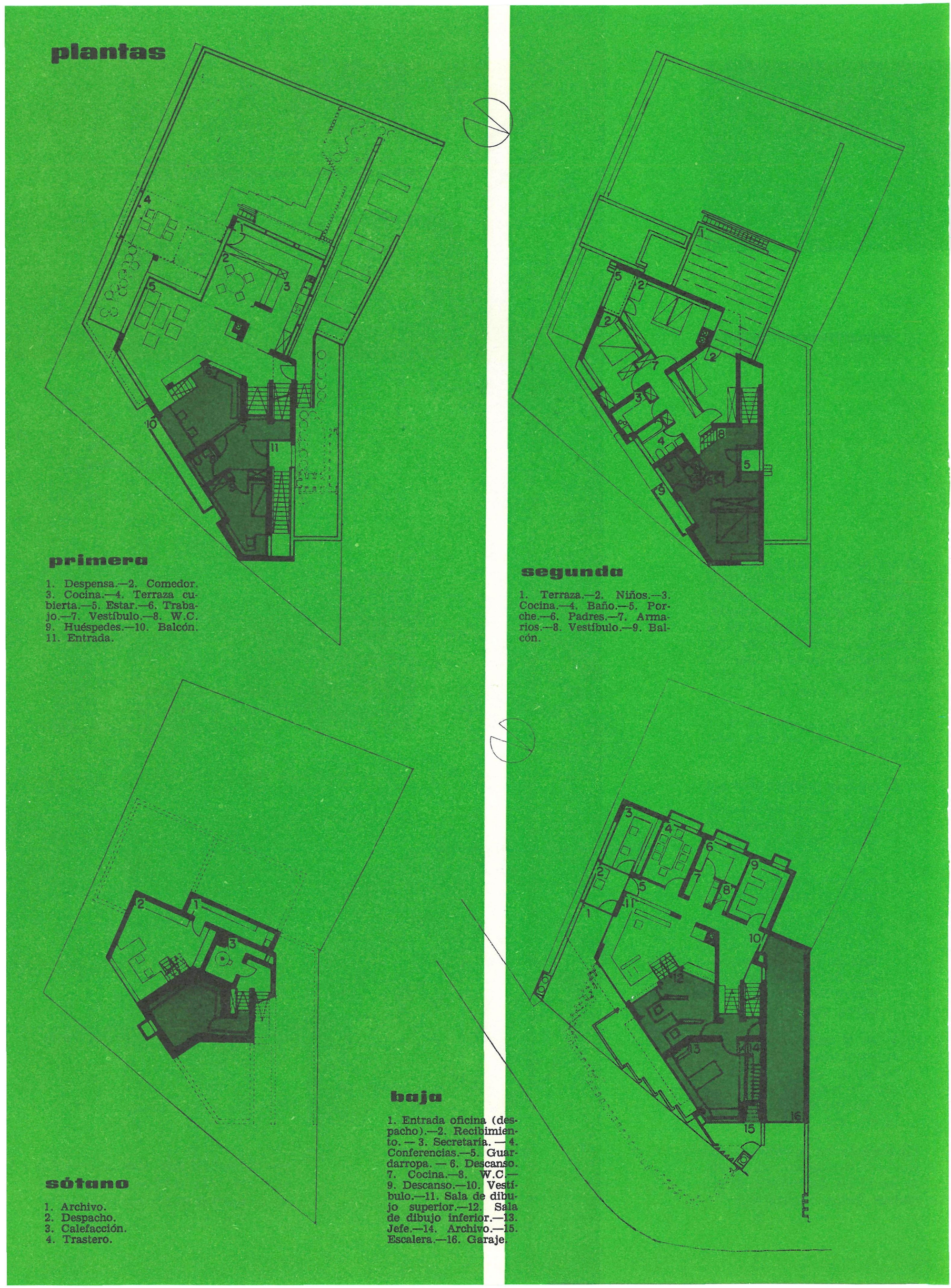



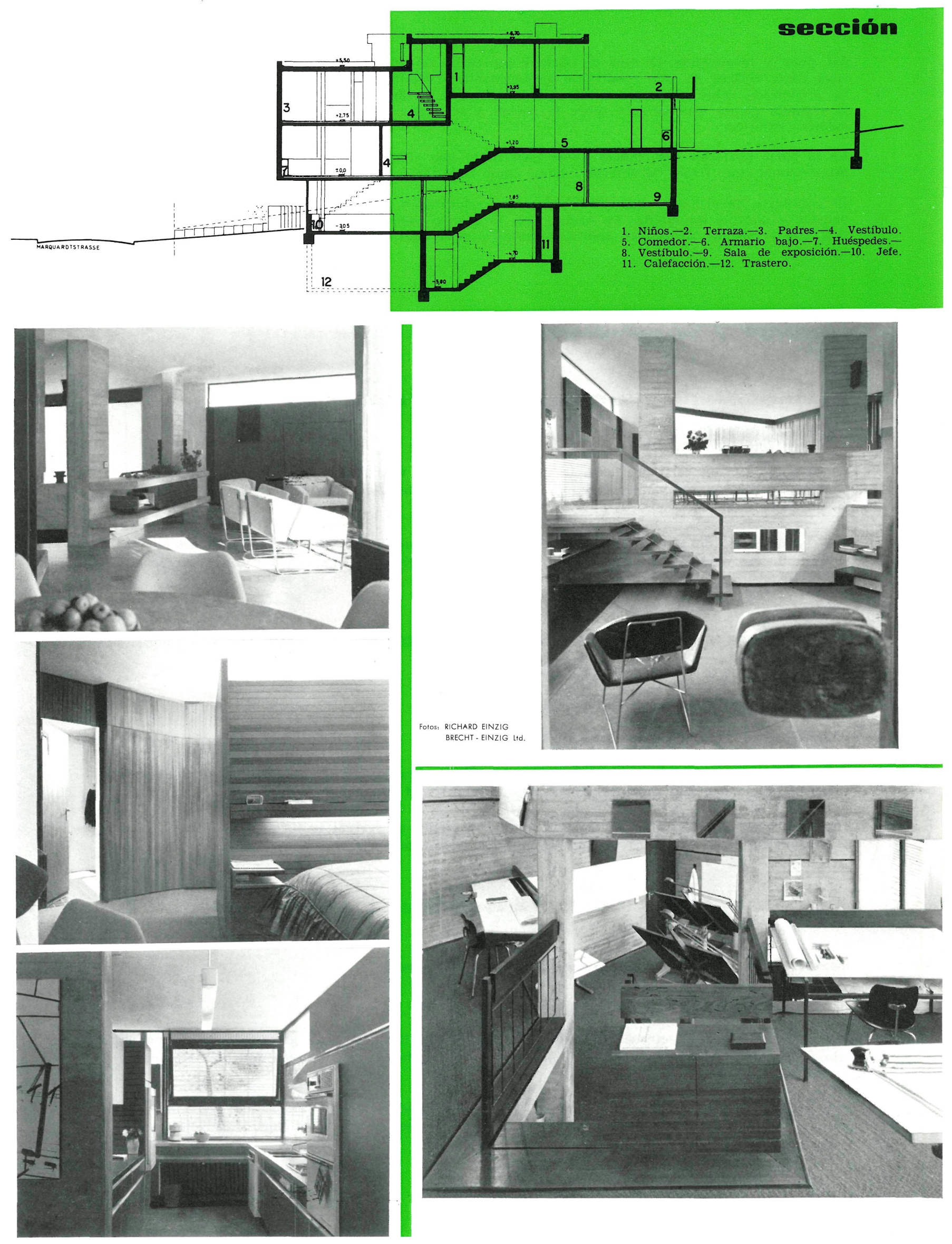
Así, pues, y resumiendo, la zona de oficinas constituye un gran recinto situado en la planta baja, cuya parte trasera ha sido construida aprovechando el declive del terreno; la zona residencial se ha organizado sobre el mismo nivel, con un pequeño jardín orientado al suroeste; la terraza de la segunda planta está situada sobre la cocina, y se puede acceder hasta ella por medio de una escalera exterior.

En la parte posterior del edificio se ha construido una chimenea de ventilación que, además de proporcionar aire fresco al interior, actúa como reflectante del ruido.

El arquitecto ha utilizado muy pocos materiales —hormigón, elementos metálicos en las ventanas, paneles y puertas esmaltadas en azul一, con lo que ha conseguido una acertada expresión plástica. Estos mismos materiales aparecen también en el interior, con un tratamiento cuidado y armónico.

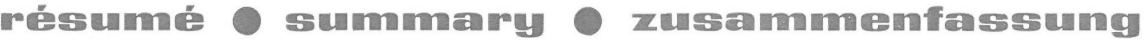

\section{Habitation-studio di Stuthgor a - Allemagne}

Wilfried Beck-Erlang, Arch. Dipl. Ing. BDA

Ce bâtiment est un véritable exemple du parti que peut tirer un projeteur en combinant avec bonheur un petit nombre de matériaux, tels que le béton, les éléments métalliques des fenêtres et les portes en émail bleu.

La forte declivité du terrain a permis d'obtenir le maximum de superficie bâtie à plusieurs niveaux et d'établir une parfaite séparation entre les dépendances destinées aux bureaux et les pièces destinées au logement de leur usager: un architecte.

\section{Home Studio in Stuthtgant, Gemmang}

Wilfried Beck-Erlang, Arq. Dipl. Eng. BDA

This building is a faithful proof of the potential effectiveness in design that is obtainable using correctly only a few materials; concrete, metal windows and blue enamelled doors.

The considerable slope of the site made it possible to build at several levels and establish a good separation between the zones devoted to offices and the home of the client, who is an architect.

\section{Wolnnstudio in Stuttgart - Deutschland}

Wilfried Beck-Erlang, Arch. Dipl. Ing. BDA

Dieses Gebäude ist ein getreuer Exponent dafür, was ein Planer aus der gelungenen Kombination sehr weniger Materialien machen kann: Beton, Metallelemente an den Fenstern und blau emaillierte Türen.

Das stark abschüssige Gelände ermöglichte es, eine maximale umbaute Fläche auf verschiedenen Niveaus zu erzielen, sowie eine perfekte Trennung zu erreichen zwischen den Büro- und Wohnräumen seines Benutzers: eines Architekten. 